\title{
The Design-Debrief: Using Storytelling to Connect Preservice Teacher Reflection With Design-Thinking
}

\author{
Stephanie Baer
}

\begin{abstract}
As a teacher educator, I prepare preservice students for regular reflection about teaching and learning by incorporating design-thinking and storytelling. In order to facilitate more interactive reflection on students' early teaching experiences, I developed the design-debrief-a classroom activity that asked students to story their teaching experience with first-graders using the design-thinking process. I make connections to how design-thinking and storytelling enabled a more complex and systematic way to approach teacher reflection.

Once upon a time, there was a group of students who were beginning to explore what it meant to teach elementary students. Every day, they would think about teaching theories, planning lessons, and classroom management. One day they had a chance to teach a real lesson to a real group of students, in a real school. Because of that, they had even more questions about the practicalities of teaching and classroom management. Because of that, their art methods instructor created a debriefing experience that asked each individual to consider real issues and potential solutions from a real teaching experience. Because of that, they considered real problems in teaching, role-played potential solutions to those problems, and discussed implications with their fellow student teachers. They not only reflected about teaching, but they also discussed and embodied real solutions to real issues they had experienced in the elementary classroom. Until finally they had a deeper understanding of what it meant to be an effective art teacher in an elementary setting.

Using storytelling as a vehicle and inspired structure, I reflect on a unique class activity I created and facilitated for my preservice art teachers during their sophomore year studying elementary art methods: the Design-Debrief. As the story explains, design-thinking provided a foundation for my students to carefully reflect on their beginning teaching experiences. Design-thinking is understood as a creative problem-solving strategy typically used by designers, but now widely seen as a cross-disciplinary approach for multiple contexts. I also draw connections between the power of storytelling and the structure of design-thinking, drawing out critical components of effective reflection.
\end{abstract}

\section{Understanding the Literature}

Reflection on teaching, design-thinking, and storytelling are concepts that have been around for quite some time with origins that cannot easily be pinpointed. While the role of reflection in teaching and learning has been widely addressed in many disciplines of research, design-thinking and storytelling in relation to education is perhaps a bit more elusive. In fact, Buchanan (1992) offers that, 
Despite efforts to discover the foundations of design thinking in the fine arts, the natural sciences, or most recently, the social sciences, design eludes reduction and remains a surprisingly flexible activity. No single definition of design, or branches of professionalized practice such as industrial or graphic design, adequately covers the diversity of ideas and methods gathered together under the label. (p. 5)

He also surmises that,

...the masters of this new liberal art [design-thinking] are practical men and women, and the discipline of thinking that they employ is gradually becoming accessible to all individuals in everyday life. A common discipline of design thinking-more than the particular products created by that discipline today-is changing our culture, not only in its external manifestations but in its internal character. (p. 21)

Avoiding the thought that this might be detrimental to the realm of design-thinking, Buchanan's (1992) larger-than-life description insinuates an over-arching connection that emphasizes process and experience over any particular product or content area. Similarly, storytelling maintains itself as a cross-disciplinary, multidimensional vehicle to the progression of human experience. Every culture within every time period made and makes use of sharing personal, communal, and cultural accounts or narratives with others. The notion of the storyteller takes many forms and is not limited to any one interpretation or methodology. In fact, for the purposes of this paper's story, Abrahamson's (1998) suggestion marks an important thought in that, "storytelling can clearly be viewed as the foundation of the teaching profession" (p. 450). In the emotional and mutual investment between storyteller and listener, new understandings can be created. "Through storytelling, the instructor can help students give up some of the limitations of their viewpoints so they can achieve a state of receptivity to the application of course content to which they are being exposed" (p. 449). The power of the medium of storytelling sets the stage both for how my students engaged with their teaching experiences as well as how I approached my own reflection of the design-debrief.

The common denominator in the seemingly varied worlds of teacher reflection, design-thinking, and storytelling is in each of their abilities to positively develop the identity of the teacher/storyteller/ design-thinker. Reflection, design-thinking, and storytelling can be effective, creative approaches to how we communicate our experiences as teachers and how we, in turn, learn from those experiences to improve practice and develop our identity.

\section{Beginning Teacher Reflection}

Reflection is a rather common process-especially for those of us in the field of education. As teachers we reflect on our teaching, student performance, assessment, class environment, learning experience, resources and materials, and the list goes on. As teacher educators, we prepare future teachers for this eventuality when we engage our preservice students in regular reflection about lesson planning, disciplinary content, teaching and learning philosophies, classroom management, student behavior, and so on. We also reflect ourselves, on how to best model the teaching we want to see in our preservice students. We gather relevant material for study and construct learning and beginning teaching experiences that communicate critical thinking, social justice, creativity, and collaboration. 
Effective and supported reflection with novice teachers is a central issue in the discourse of education. It is undisputed that in order for a teacher, especially a novice teacher, to be effective, well balanced, and resilient, reflection must be part of their practice (Conway, 2001; Dewey, 1910; Palmer, 1998; Schön, 1983, 1987; Van Manen, 1995). There is also consideration for reflection's relationship to teacher efficacy and autonomy whereby the practice of reflection can result in higher efficacy and autonomy (Noormohammadi, 2014) and positively alter thinking and behavior (Bandura, 1986). It is also understood that effective reflection on teaching practice is a developmental process and not innately carried out (Parikh, Janson, \& Singleton, 2012). Noormohammadi (2014) and Dyment, O'Connell, and Boyle (2011) describe the need for training and feedback in reflective process. Yost (2006) affirms this idea in asserting that, "teachers need knowledge of how to reflect as well as time to think about their practice" (p. 61). Jarvis (1992) describes her participants' heightened sense of responsibility with the use of written diaries for teaching reflection. There are also several studies that examine the quality, type, and depth of reflection (Lee, 2005).

In response to the regular and expected practice of reflection, I try to stray from the common written format as much as possible within my art methods classes. I want my students to utilize the creative process in conjunction with their pedagogical studies and understand art as a way of thinking, rather than simply a content area. In an effort to engage my preservice students in more interactive reflection on their beginning teaching experiences, I looked to the realms of design-thinking and storytelling. My initial thought was that these more experiential mediums might yield more complex reflections and a deeper understanding of their teaching experiences.

\section{Design-Thinking in Education}

According to IDEO, a global design company created in 1991, the five steps of the design-thinking process are: empathize, define, ideate, prototype, and test (see Figure 1). Because my preservice art education students are heavily involved in studio art curriculum as well as teaching methods, the design-thinking process seemed to be a natural organization of what they already understood about creating artwork. An artist empathizes with some type of idea or need to create, defines a media, ideates how that idea might be visually represented using that media, prototypes by composing sketches and working with the media to create representations of their ideas, and tests the final piece through exhibition or inviting others to interact with process/product. Of course, not all artists work within this process, but design thinking adds a language and structure to what is often a more subtle or undefined process. Both endeavors (artists' creative process and the design-thinking process) encourage a nonlinear and creative approach that invites deeper, more comprehensive reflection. 


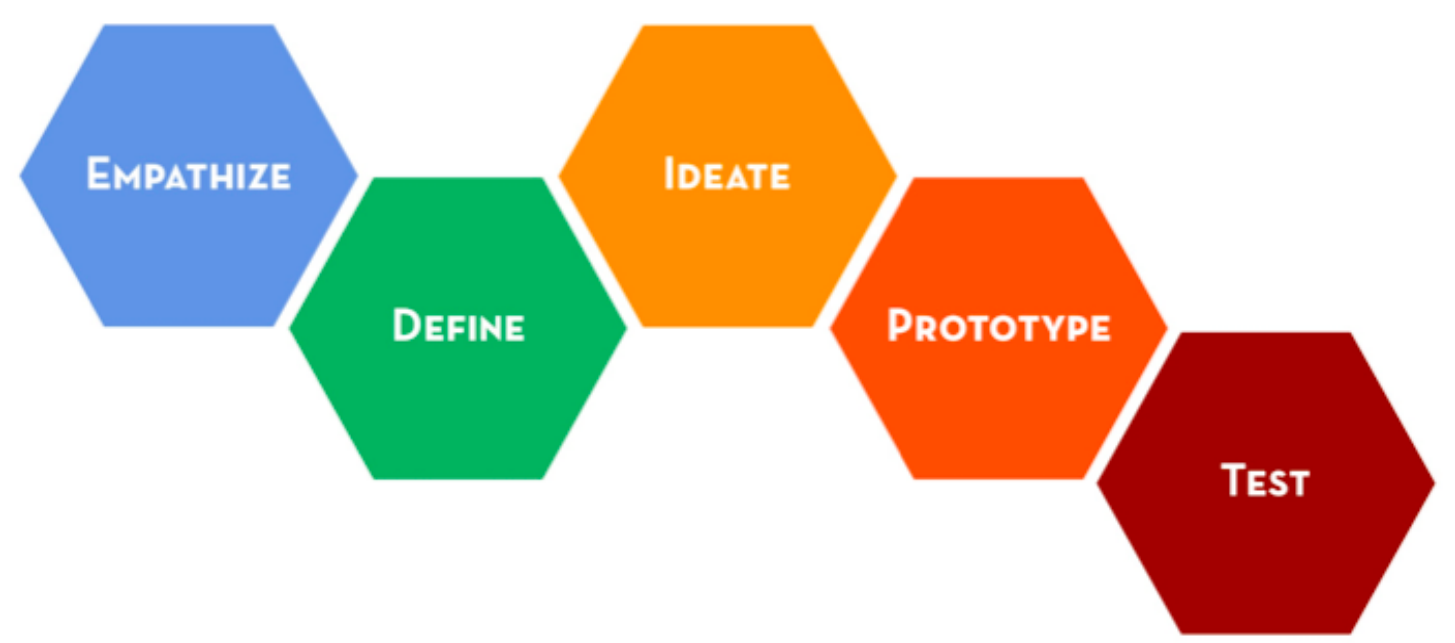

Fig. 1: Design-Thinking Process conceptualized by IDEO and illustrated by the Stanford d-school.

The origins of the intersections between design-thinking and education cannot necessarily be pinned down, but can be tracked through a review of research that spans various fields like engineering, graphic and communication design, as well as visual arts. In Razzouk and Shute's (2012) review of design thinking and its importance, they identify not only prominent characteristics of design thinking, but also distinguish between features of novice and expert design-thinkers as well as describe the capability of design-thinking to promote problem-solving skills. Referencing many studies on design thinking and education, Razzouk and Shute (2012) say the difference between expert and novice design-thinkers could be the focus on the solution, rather than the problem.

...building experience in a particular domain allows designers to quickly identify the problem and propose a solution. Generating, synthesizing, and evaluating a solution are frequently identified as key features of design expertise... creative and productive design behavior seems to be associated with frequent switching of types of cognitive activity. (p. 343)

These authors go on to describe the critical nature of experiencing the process of design-thinking and its usefulness within the classroom and beyond.

Helping students to think like designers may better prepare them to deal with difficult situations and to solve complex problems in school, in their careers, and in life in general. Current educational practices, though, typically adhere to outdated theories of learning and pedagogy, evidenced by a so-called content fetish (Gee, 2005). That is, schools continue to focus on increasing students' proficiency in traditional subjects such as math and reading, via didactic approaches, which leaves many students disengaged. (p. 343)

Having good design thinking skills can assist in solving really complex problems as well as adjusting to unexpected changes. Although the design process involves in-depth cognitive processes - which may help our students build their critical thinking skills (e.g. reasoning and analysis) - it also involves personality and dispositional traits such as persistence and creativity. (p. 345) 
This connection between design-thinking and developing productive dispositional traits is especially pertinent within the realm of teacher education. It affirms the nature of critical thinking as a process and one to be learned and developed alongside experience within the field. Teaching and learning within the visual arts is inherently an experiential journey and thus can perhaps mimic the structure and process of design-thinking where extended experience, creativity, and solution-focused exploration is central.

\section{Storytelling in Education}

In a 1997 conference focusing on stories and storytelling in education, the proceedings coeditor and conference coordinator begins with,

Stories live everywhere, but rarely stay in one place. Despite our attempts to classify, codify, and construe them, stories keep moving too mercurially to fit intellectual categories. Stories also shape change. They shrink or expand depending on the listener, the medium, the time, the place, and the teller (Hearne, 1998, p. 2).

In the final paragraph of her introduction, she offers that, "Good storytelling makes education an entertaining experience and entertainment an educational experience" (p. 2). She also points out the connection between the learning that occurs during storytelling and play. This connection aligns with Macintyre Latta and Hostetler's (2003) consideration of the "call to play" where the idea behind play and dialogue is that we enter into these acts and then exit them constantly, always changing and being transformed from who we were upon entering. They suggest the idea of "catching oneself" in the act of teaching and how educators must rethink, revise, reconsider, and ultimately play with their teaching role to better understand and develop it. Walsh (2007) said that, "Whoever tells the stories defines the culture" (p. 24). Thus, in developing future teachers' ability to examine and reexamine their teacher selves and experiences in the classroom, we are asking them to story their evolving culture. They become the storytellers, ready to reflect on and suggest change for the future.

Abrahamson (1998) suggests that, "Storytelling develops a context for active learning and remarkable ownership of the learning, both in terms of process and content" (p. 450). McDrury and Alterio (2002) expand that idea, describing storytelling as a theory of learning. They address storytelling pathways that consider multiple listeners and contexts and how a student's choice of pathway can transform his or her reflective ability. McDrury and Alterio borrow from Moon (1999) and Entwistle (1996) in creating a Reflective Learning through Storytelling model (McDrury \& Alterio, 2002, p. 60). The model creates a spectrum of learning based on story finding, telling, expanding, processing, and reconstructing. Alongside the stages of learning, storytelling outcomes are described in terms of reflection, release, and changes in practice. This suggests that in the exploration and restructuring of stories, that greater understanding can occur, and thus potential change to practice. Strauss's (2011) collection of "story solutions" offers hope that through the telling and discussion of stories, issues like bullying, drug prevention, and conflict resolution can be more effectively addressed. He references Sima and Cordi's (2003) work indicating that, "telling stories also gives children a chance to practice public speaking skills 
and develop confidence in their ability to communicate with others" (Strauss, 2011, p. xv)—vital skills needed for teachers as well.

\section{Connections Between Design-Thinking, Storytelling, and Teaching}

As I was developing the design-debrief, I was struck by the similarity between design-thinking and the storytelling structure outlined by Karia (2015). Karia (2015) synthesized a list of five basic elements of a good story as illustrated by the most successful TED talks. He names character, conflict, spark, change in character, and take-away as the most present and important parts of the most-watched TED talks. The phenomenon of the TED series has created a new methodology for engaging in storytelling. The worldwide acknowledgment of how an individual story can spark change and wider discourse on difficult issues has given storytellers new and crucial consideration (Anderson, 2016). However, are we teaching future generations how to tell those important stories? Are we equipping the next generation of teachers to engage their students using stories and creative methodologies for thinking and learning?

As we engage in the creative process as artists, we are constructing and telling a story with some type of media with the intent to communicate that story to ourselves and others. As we engage in the creative process as teachers, we can capture the same fluid nature of the design process. Teaching, lesson-writing, and reflecting are all creative acts if we seek to experience them this way. When done so, the result can create a multi-tiered understanding to the creative act of teaching. Bringing together a wider understanding of how the design-thinking process overlaps and weaves within the elements of storytelling can add power to the message we want to send.

When comparing and connecting the steps of design-thinking and the elements of a story (see Figure 2), the greater purpose behind each collection of ideas becomes more apparent.

\begin{tabular}{|l|l|l|}
\hline Design Process & Elements of a story & Connection \\
\hline Empathize & Character & $\begin{array}{l}\text { We create/describe a character that others } \\
\text { empathize with. }\end{array}$ \\
Ideate/Refine & Conflict & $\begin{array}{l}\text { We define a problem or conflict, setting the } \\
\text { scene/context. This helps us better understand } \\
\text { the character and purpose. }\end{array}$ \\
Prototype & Spark & $\begin{array}{l}\text { We think of ideas, brainstorm, eventually } \\
\text { arriving at a spark of inspiration. }\end{array}$ \\
Test/Present & Change in Character & $\begin{array}{l}\text { We choose an idea and embody/test it to create } \\
\text { change (in a character/situation). }\end{array}$ \\
\hline
\end{tabular}

Fig. 2: Connecting the steps of the design-thinking process and elements of storytelling.

In both the design-thinking process and in storytelling, the designer/storyteller/teacher is trying to communicate a message effectively for a given audience. In order to do that, the designer/storyteller/ teacher has to be aware of the contextual elements of their process, audience, and form-whether that be a designer developing a product design, a storyteller weaving together a narrative, or a teacher constructing a learning experience. In other words, each creator must both know his or her content well 
(e.g. product design, story, learning goals) and exert effort and skill in how that message is communicated. The communicator is just as necessary as the message and carries much of the intended meaning. A design must be created; A story must be told; A lesson must be taught. Delivery matters.

At their very best, teachers are storytellers. They engage their audience (students, colleagues, administrators, parents, etc.) with important content and strive to present lessons worth learning. At their very best, teachers are designers. They take the time to consider various perspectives and methodologies for how to present and teach information, media, and experiences. Effective teachers are consistently reflective and can enter that same creative process with how they think about their teaching as well. The steps of the design-thinking process and the elements of storytelling can create a framework for how my preservice students could engage in thoughtful and comprehensive reflection.

\section{The Characters and Context for Reflection}

In the fall of 2017, my elementary art methods made new meaning of their beginning teaching experiences in a design-debrief process. Our class, comprising 13 first- and second-year art education majors, was invited to teach a series of three visual art lessons to the first-graders at a local elementary school. In order to prepare teaching the first-graders, my preservice art education students were put into four teaching groups of three to four students each. Every preservice student would have the opportunity to be lead teacher for one of the three sessions at the elementary school and serve as an assistant teacher for the remaining two lessons. The students had varying levels of comfort and experience in working with elementary students. Planning and teaching these 20-minute lessons as part of an elementary art methods course gave them an opportunity to get their feet wet alongside peer support with a well-structured pre- and post-teacher education lesson in place. The pre-lesson afforded them the opportunity to see modeled instruction, build a lesson plan with instructor and peer feedback, and practice their teaching with peers. With each step in their teaching preparation, the preservice students were reflecting both in writing as well as class discussion. The post-lesson, the subject of this paper, was a debriefing session where students engaged in reflection that was structured around the design-thinking process and storytelling. After a description of the Design-Debrief steps, I will make connections to how designthinking and storytelling enabled a more complex and systematic way to approach the reflection process.

Student perspectives on this special debriefing session will be shared as well as suggestions for facilitating similar reflective experiences.

\section{The Design-Debrief}

Following their first elementary teaching experience with the first-graders, I told my preservice art methods students that we would be debriefing their experience using the design-thinking process and a classroom assessment technique called invented dialogues (Angelo \& Cross, 1993) where students roleplay using dialogue they construct themselves. A few of the students had exposure to the design-thinking process in other courses, but the majority of the 13 students were not familiar with it and none were familiar with invented dialogues. I gave a brief introduction to the steps of the design-thinking process 
we would navigate together. While storytelling was not explicitly explained to the students beforehand, each step engaged them in a form of storytelling (see Figure 2).

We began class with a handout and PowerPoint presentation that communicated the day's goals to the students:

The goal of this class activity is for students to synthesize their knowledge of teaching issues and strategies in a specific context into the form of a carefully structured, illustrative conversation, using the design process as a guide. Other teaching goals associated with this process allow students to:

- Develop ability to draw reasonable inferences from observations

- Develop ability to synthesize and integrate information and ideas

- Analyze various strategies and techniques through discussion and collaboration

- Evaluate potential solutions and test them through role-play and presentation

While these goals presented a complex set of tasks, the design-thinking process guided us through each step. Prior to arriving to class, the students reflected individually in written form to begin a personal analysis of their group's teaching experience. This primed them to begin group analysis upon arriving to class.

Empathize. First, the students shared their reflections of the first teaching experience with their group. They referenced their individual reflections identifying major issues, questions and concerns they had, and any other observations worth mentioning. As expected, classroom management was a hot topic for several of the groups as this is a central focus of preservice and beginning teachers.

Within each group, the students took turns preparing to be the lead teacher for each teaching session at the elementary school. They each were required to plan, write, and execute a lesson plan focusing on talking about art with first-graders. All students had also been placed in varied different elementary art classrooms for semester-long observations. This shared experience resulted in varied perspectives on similar issues and allowed for relevant suggestions to be brought forward. The students also practiced empathy with one another (see Figure 3), working to understand the whole of the others' experience in the classroom.

Define. From the discussion, the students then identified a central issue to focus on based on their shared observations in the first-grade classroom. For example, one group experienced difficulty in gaining the first-graders' attention after the first-graders were asked to discuss with their neighbor. Once the issue was identified, each group formed a "How Might We" statement so they could more definitively state the issue or problem they encountered as well as the desired outcome. The structure of the statement needed to follow this format: "How might we [actor + action] so that [desired result]?" For example, the group having trouble gaining first-grader's attention came up with: "How might we bring the focus back to distracted students so that they stay engaged?" In this step, the preservice students were beginning to focus their story toward a more structured telling. They were identifying the conflict present within their teaching space and discussing how they envisioned influencing a change in first-graders' behavior. 


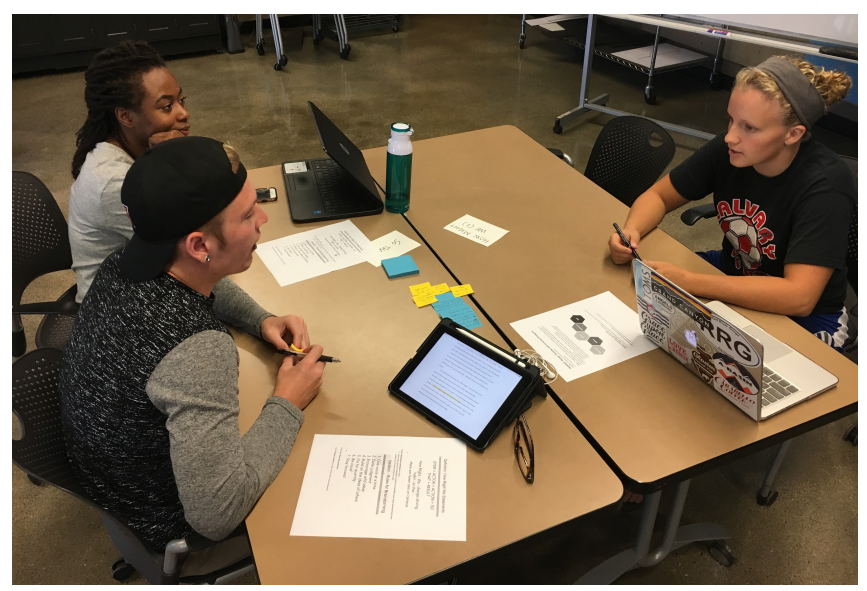

Fig. 3: Students sharing reflections with one another in the first step of the design-debrief process.

Ideate. Next, the groups brainstormed solutions to the potential issue. How could they get from the problem to the desired outcome? A list of ideation rules (Ideo.org, 2017) were posted as the students worked to encourage creative and plentiful discussion:

1. One voice at a time

2. Defer judgment

3. Encourage wild ideas

4. Build on the ideas of others

5. Go for quantity

6. Be visual

7. Stay focused

Groups were given a whiteboard to visually record all ideas. This enabled all group members to stay focused on the task at hand and consider all options as they worked to find solutions to their chosen issue (see Figure 3). The students furiously took note of all ideas-realistic or idealistic-deferring judgment and censoring for later. In this stage, they were searching for a spark, an inspiration that might offer a solution to the problem they'd identified.

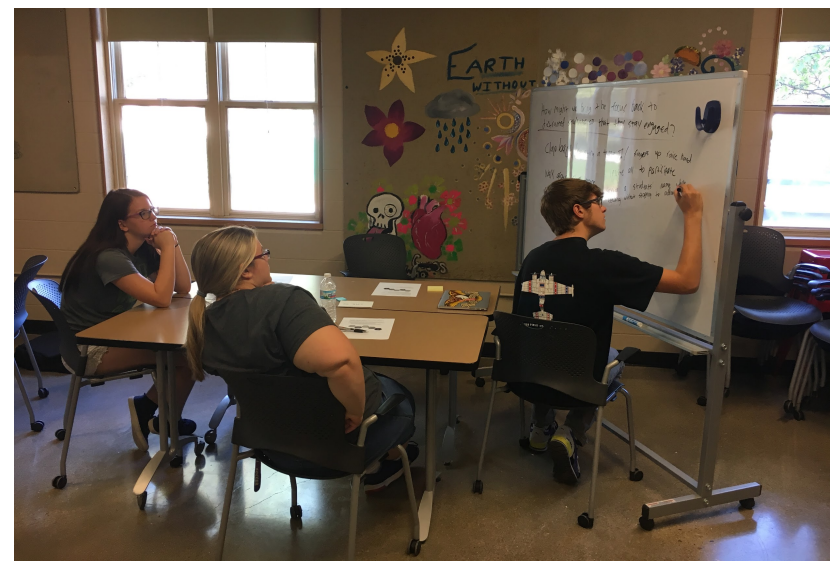

Fig. 4: Students brainstorming solutions and recording ideas visually in the third step of the design-debrief process. 
Prototype. After the groups spent around 10 to 15 minutes brainstorming solutions, they began the prototype step. For this step, the students role-played some of the solutions they came up with. This exercise, similar to Angelo and Cross' (1993) invented dialogues, required students to step outside their comfort zone and practice some of the teaching techniques they were coming up with. The assistant teachers in each group role-played first-graders, while the student who lead-taught the lesson the week before at the elementary school role-played the teacher and revisited the defined issue with potential solutions. The groups then debriefed and decided which strategies might be most effective.

The students tried on different ideas. They were entering in and out of different versions of their teaching story, looking to hone their skills and more quickly adapt to difficult situations. With each prototype, the group would assess and reassess working to identify the characteristics of each proposed solution and what would best fit their teaching context.

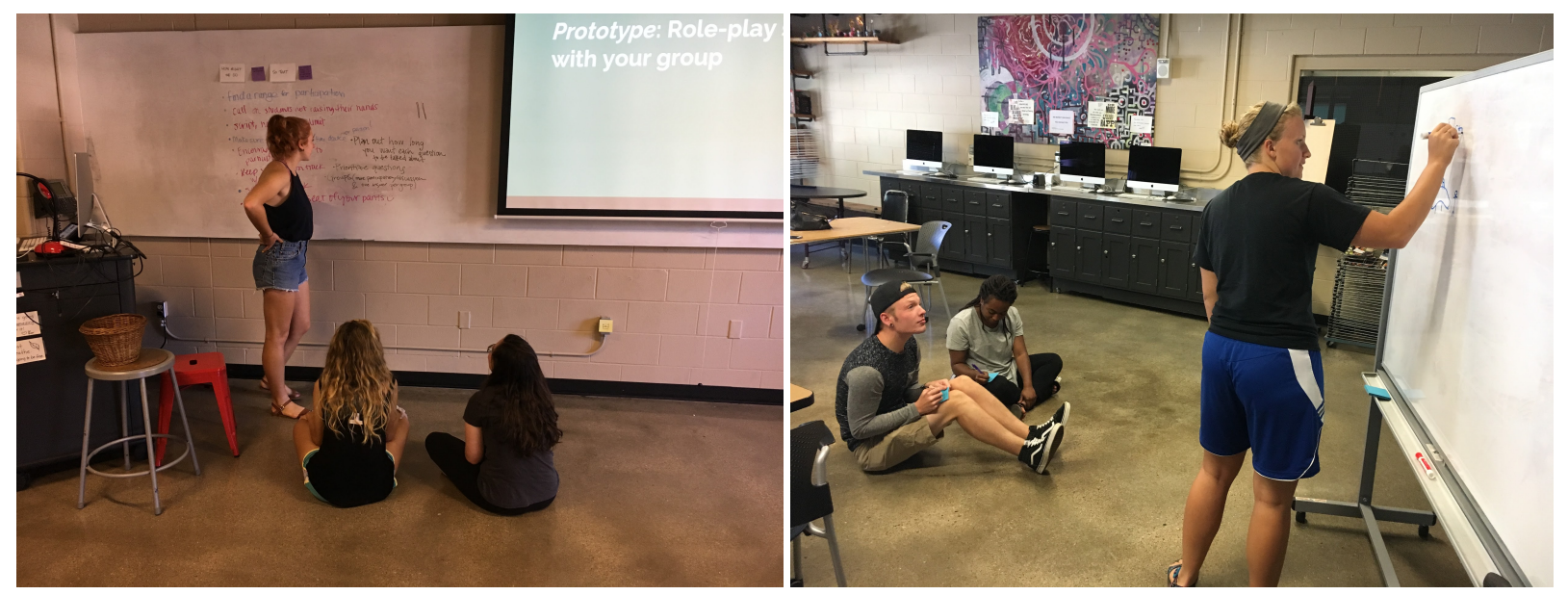

Fig. 5 and Fig. 6: Students prototyping brainstormed solutions with their group for the fourth step of the design-debrief process.

Test. Once the groups had the opportunity to choose what they thought would be the best solution thus far for their chosen issue, they tested their ideas out on the class as a whole. In turn, each lead teacher presented their solutions in continued role-play while the remainder of the class role-played as first-graders (see Figures 7-8). After each lead teacher role-played a four-to-six-minute situation, including their group's chosen solution, the whole class debriefed together and gave feedback.

Inevitably, the classroom stories that the groups worked with to identify both their issue and proposed solutions surfaced as they presented their ideas to the class. The groups felt compelled to give a wider context to help their audience understand the elements they were working with (e.g. disruptive students, noise levels, etc.). In turn, each group became storytellers of its teaching experience and in that telling, students reflected both on their own experience and that of others. They built a collective understanding of best practices, developed greater empathy for one another (and their cooperating teachers), and had a deeper sense of what others were navigating as beginning teachers. 

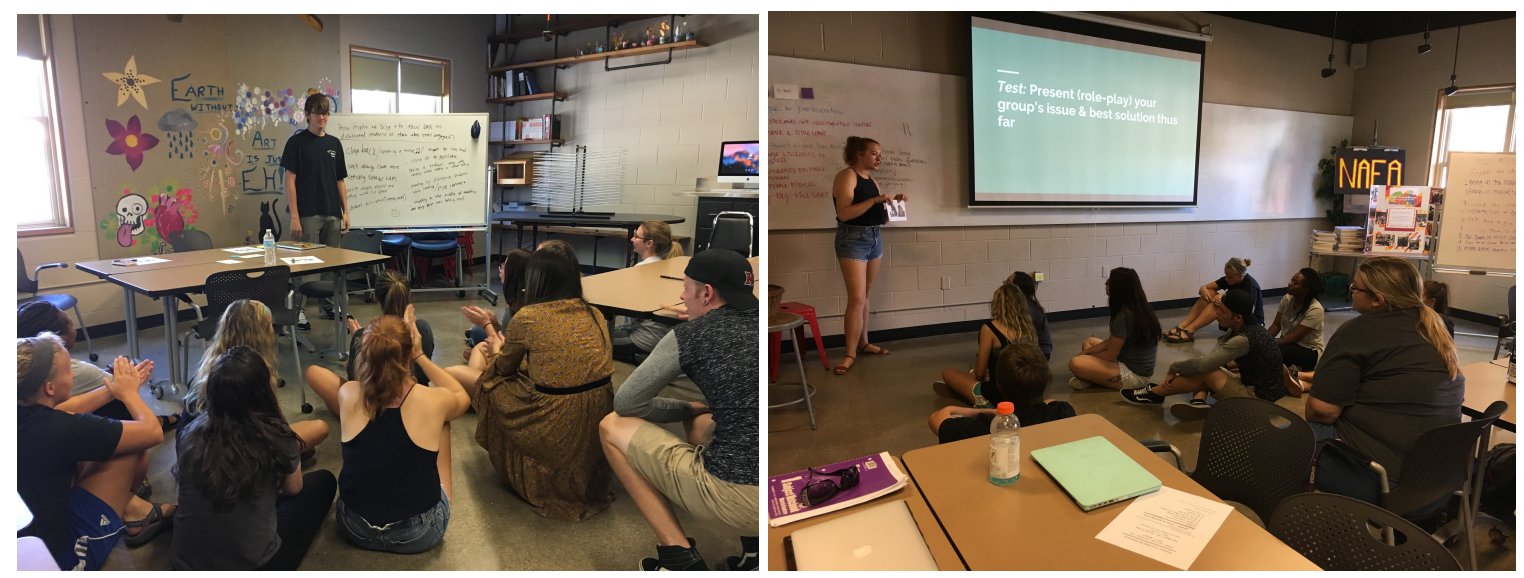

Fig. 7 and Fig. 8: Students testing chosen solutions for entire class for the fifth step in the design-debrief process.

The five steps in the design-debrief process were meant to circulate and not follow a linear pattern that ended after step five. The strength of the process was in the continual reworking and reconsideration of ideas to make them stronger. These preservice students returned two more times throughout the semester to teach the first-graders at the elementary school and had the opportunity to debrief after each session. While debriefing didn't always follow the design-thinking steps explicitly, the students had initially engaged in a reflective process that honored everyone's voices and stories, gave opportunity for contextual expertise, allowed for failure, and encouraged multiple solutions. This experience also invited the teaching teams to trust one another and become closer as they navigated their personal and professional perspectives on their teaching experience.

\section{The Take-Away}

While I'd like to say my students and I engaged in a flawless process of the design-debrief, I cannot. There are things I would change about how I led the experience and approaches I would try to increase student understanding and engagement. In a blog post entitled, 22 \#storybasics I've picked up from my time at Pixar, Emma Coats shared, "Finish your story, let go even if it's not perfect. In an ideal world you have both, but move on. Do better next time." Following Coats' example, the "letting go" is part of the creative process - it's how we arrive at new ideas and truly engage in reflective thinking that focuses on solutions, rather than fixating on problems. It also gives us the opportunity to engage with others, get feedback, and move beyond a singular perspective-a trajectory crucial for teacher growth. In that vein, I surveyed my preservice students following their design-debrief experience. Here is what we learned:

Brainstorming (ideating) as a group is a critical step: When asked what the most helpful element of the designdebrief experience was, many students mentioned the opportunity to brainstorm together both as a small group and as a class. One student said, "Coming up with ideas together was really helpful and I feel like I have new ideas for my lesson." Another mentioned, "writing down ideas and brainstorming with no bad ideas was helpful! It made me really think about how many ways you can go about one thing." When asked what they would do to improve the design-debrief experience, the need for discussion came up again. One student suggested more 
time be allowed for groups to brainstorm. Another wanted to add a larger class discussion after the small group discussions. One student offered the idea to collect all groups' written ideas in writing, so everyone had the benefit of all group solutions. "That way we can gather and keep the ideas shared so we can look back to them rather than just seeing them."

Role-playing can be awkward: Expectedly, there was some discomfort around the role-playing activity. "I do not enjoy acting it out to the class. I get the idea, but we are not first-graders, so we aren't going to act like them...it's a little uncomfortable." One student believed, "testing them in our classroom was not helpful since it will truly be applied in the actual school setting." Another student simply said, "I don't think the role-playing was necessary." On the other side of the spectrum, one student offered, "I liked acting out the solutions to see how effective they are." Another said, "The acting out was kind of difficult, but I see why we did it." Still another admitted, "It was a bit stressful to do a roleplay at first, but stress is good, it helps us grow!" I have encountered this love-hate relationship with performance in class many times as a teacher-at all grade levels. Performing can be a difficult task when you are experimenting with new ideas. Though these students had been in class together, their comfort with one another was not completely established. As the instructor for the class, the design-debrief process was one way I was attempting to foster greater trust between the students-but that trust-building needed to begin before that day. Often it is the fear or discomfort that creates openings for greater understanding of self and other (Baer, 2012; Dewey, 1904).

Structure matters: As the instructor in this context, having a structure created expectations both for me and for the students. They knew what to expect and what role each step was intended to play. Breneman and Breneman (1983) suggest that in order to work with a story, one must first break it down and analyze its parts-both logistically and emotionally addressing tone, mood, theme, character, and plot. They suggest framing the theme in a single statement. Like our "How Might We" statements in step two of the design-debrief, the storytellers are asked to consider a more succinct and direct telling in order to pinpoint the desired outcome.

Often, open reflection can go one of two ways: If the students "buy in" and are ready to consider their experience and describe it to others, the class can have a rich experience sharing out. However, simply diving in with opened-ended questions like, "How did it go?" or "What did you think?" can leave many students clinging to surface impressions of their experience, or leave them to rely on the most verbose classmates to dominate the discussion. Open-ended reflection can also fall flat very quickly for these reasons. In the design-debrief, the structure added a democratic approach where all voices were needed and seen as full of potential. Everyone's experience mattered, and the breadth of learning depended on the contribution and collaboration of group members. There was accountability with the use of small groups, which then translated well as we came together as a whole class to offer solutions to one another.

When students were surveyed, I asked them if they would like to engage in a design-debrief after the following two first-grade lessons that would be taught at the elementary school. Despite the discomfort in role-playing and some students' preference for written reflection, all students responded with a resounding, "Yes." 


\section{Concluding Thoughts}

In reflecting on the design-debrief experience, I was inspired by animator and storyteller, Emma Coats' offering of how Pixar creates their successful stories. Number four on her list offers a particular structure to sequence a holistic understanding of a story. "Once upon a time there was___. Every day, ___. One day__. Because of that, __. Until finally __.." (see introduction paragraph for the design-debrief story). Coats suggests to storytellers that they empathize with their character, consider the rationale behind why they want to write, and "pull apart" the stories they like-recognizing particular elements and connections within a story. Another poignant bit of advice: "You have to know yourself: the difference between doing your best and fussing. Story is testing, not refining" (Coats, 2013). The design-thinking elements in Coats' advice are striking and guide storytellers to consider both structure and openness as they approach their creative process.

The preservice students I worked with during the design-debrief activity engaged in a reflective experience that can be simultaneously described as both open and structured. In order for them to more fully reflect on their beginning teaching experiences with depth and complexity as well as to become accomplished communicators of that experience, they embodied storytellers and design-thinkers. The structure of an effective story carries an important message and allows the audience to more fully engage in empathy with the characters involved. It considers conflict a necessary step in growth and highlights inspiration, allowing for characters to grow and develop throughout a story. Rather than stifle the creative telling of an experience like teaching, the storytelling structure and design-thinking process add succinct eloquence that absolutely requires and begins with open reflection. Consider the possibilities of growth if that reflection is carefully guided by a process grounded in empathy and ideating, champions mistakes as much as success, and invites an iterative approach to understanding. Not only would the storyteller/designer/teacher have a more comprehensive understanding of their experience, but they also encounter a more holistic idea of how they played a part, individually, within that educative experience. Perhaps the differences between storytellers, designers, and teachers are not so extensive, but rather beautifully similar as communicators of the human experience.

\section{References}

Abrahamson, C. E. (1998). Storytelling as a pedagogical tool in higher education. Education, 118(3), 440-450.

Anderson, C. (2016). Ted talks. Boston, MA: Houghton Mifflin Harcourt.

Angelo, T. A., \& Cross, K. P. (1993). Classroom assessment techniques. A handbook for college teachers. Second edition. San Francisco, CA: Jossey-Bass.

Baer, S. (2012). The fear of art and the art of fear. Education and Culture, 28(1), 42-61.

Bandura, A. (1986). Social foundations of thought and action: A social cognitive theory. Englewood Cliffs, NJ: Prentice-Hall. 
Breneman, L., \& Breneman, B. (1983). Once upon a time: A storytelling handbook. Chicago, IL: Nelson-Hall.

Buchanan, R. (1992). Wicked problems in design thinking. Design Issues, 8(2), 5-21.

Coats, E. (2013). 22 \#storybasics I've picked up in my time at Pixar [Web log post]. Retrieved from http://storyshots.tumblr.com/post/25032057278/22-storybasics-ive-picked-up-in-my-time-at-pixar

Conway, P. F. (2001). Anticipatory reflection while learning to teach: From a temporally truncated to a temporally distributed model of reflection in teacher education. Teaching and Teacher Education, 17, 89-106.

Dewey, J. (1904). The relation of theory to practice in the education of teachers. In C. A. McMurry (Ed.), The third yearbook of the national society for the scientific study of education (pp. 9-30). Chicago, IL: The University of Chicago Press.

Dewey, J. (1910/1997). How we think. New York, NY: Dover Publications, Inc.

Dyment, J. E., O'Connell, T. S., \& Boyle, I. (2011). The intersection of web 2.0 technologies and reflective journals: An investigation of possibilities, potential and pitfalls. Journal of Outdoor Recreation and Leadership, 3(3), 137-150.

Entwistle, N. (1996). Recent research on student learning and the learning environment. In J. Tait \& P. Knight (Eds.), The management of independent learning. London: SEDA/Koan Page Limited.

Gee, J. P. (2005). What would a state of the art instructional video game look like? Innovate, 1(6). Retrieved from http://www.innovateonline.info/index.php?view= article\&id=80.

Hearne, B. (1998). Introduction. Story: From fireplace to cyberspace: Proceedings from Allerton Park Institute, No. 39. Monticello, IL: University of Illinois at Urbana-Champaign.

Ideo.org. (2017). Brainstorm rules. Retrieved from http://www.designkit.org/methods/28

Jarvis, J. (1992). Using diaries for teacher reflection on in-service courses. ELT Journal, 46(2), 133-143.

Karia, A. (2015). TED talks storytelling. CreateSpace Independent Publishing Platform. Retrieved from https://www.amazon.com/TED-Talks-Storytelling-Techniques-

Best/dp/1507503008/ref=asap_bc?ie=UTF8

Lee, H.J. (2005). Understanding and assessing preservice teachers' reflective thinking. Teaching and Teacher Education, 21, 699-715.

Macintyre Latta, M., \& Hostetler, K. (2003). The call to play. International Journal of Education and the Arts, 4(3).

McDrury, J., \& Alterio, M. (2002). Learning through storytelling in higher education. London: Kogan Page.

Moon, J. (1999). Reflection in learning and professional development. London: Kogan Page Limited.

Noormohammadi, S. (2014). Teacher reflection and its relation to teacher efficacy and autonomy. Procedia - Social and Behavioral Sciences, 98, 1380-1389.

Palmer, P. J. (1998). The courage to teach: Exploring the inner landscape of a teacher's life. San Francisco, CA: Jossey-Bass Publishers. 
Parikh, S. B., Janson, C., \& Singleton, T. (2012). Video journaling as a method of reflective practice. American Counseling Association, 51, 33-49.

Razzouk, R., \& Shute, V. (2012). What is design thinking and why is it important? Review of Educational Research, 82(3), 330-348.

Schön, D. A. (1983). The reflective practitioner. New York, NY: Basic Books.

Schön, D. A. (1987). Educating the reflective practitioner. San Francisco, CA: Jossey-Bass Publishers.

Sima, J., \& Cordi, K. (2003). Raising voices: Creating youth storytelling groups and troupes. Teacher Ideas Press.

Strauss, K. (2011). Story solutions: Using tales to build character, teach bully prevention, drug prevention, and conflict resolution. Santa Barbara, CA: Libraries Unlimited, ABC-CLIO.

Van Manen, M. (1995). Epistemology of reflective practice. Teachers and Teaching: Theory and Practice, $1(1), 33-50$.

Walsh, D. (2007). No: Why kids of all ages need to hear it and ways parents can say it. New York, NY: Free Press.

Yost, D. S. (2006). Reflection and self-efficacy: Enhancing the retention of qualified teachers from a teacher education perspective. Teacher Education Quarterly, 59-76.

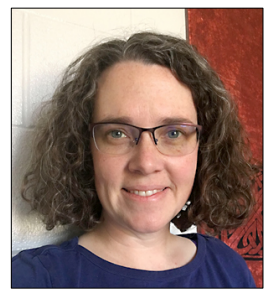

Stephanie Baer is an Assistant Professor of Art Education at Miami University in Oxford, Ohio. She received her Bachelor of Fine Arts, Masters in Secondary Teaching, and $\mathrm{PhD}$ in Educational Studies at the University of Nebraska - Lincoln. She taught middle and high school art in Kansas and Colorado before returning to the postsecondary classroom. Baer's dissertation, "Re-Envisioning Fear: The Role of Conversation in an Arts Classroom for Prospective Teachers," won the 2014 American Educational Research Association Arts and Learning Dissertation Award. Her research interests lie in preservice art teacher education, novice teacher experience and advocacy, and teacher confidence. 
76 | LEARNing Landscapes | Spring 2018, Vol. 11 No. 2 